\title{
EXISTENCE OF PROFESSIONAL INSTRUCTIONAL DESIGNER IN INDONESIA
}

\author{
Dr. Purwanto \\ Chairman of Indonesian Instructional Designer Associatio \\ purwanto@kemdikbud.go.id
}

\begin{abstract}
The purpose of this paper is to introduce PTP (Pengembang Teknologi Pembelajaran), namely instructional designers in Indonesia, who have received recognition from the government as one of the profession of education staff. The presence of Instructional Designer in Indonesia began with the enactment of the MENPAN RI Regulation in 2009. Instructional designer or PTP positions began to be implemented since 2011 with the appointment of a number of civil servants to PTP through inpassing. Since then the number of PTP has continued to increase and spread in various agencies within the Ministry of Education and Culture and in other Ministries and Institutions throughout Indonesia. They work to develop ICT-based learning models and support the tasks of educators in conducting innovative learning using a variety of learning resources and media.PTP acts as an educator working partner in realizing the application of distance learning models, blended learning or other ICT-based learning models needed in various types of education ranging from early childhood education, primary and secondary education, higher education and training in professional positions. Various efforts have been made by the Ministry of Education and Culture as an institution to foster PTP functional positions so that PTP has now become one of the professions that are becoming well known and fostered in a modern way. In-service training is carried out in a hybrid manner, combined between face to face and online. Likewise, credit number assessment activities are also carried out online without using paper. Competency testing is also conducted online. Professional organizations have also been formed which accommodate all PTPs in Indonesia, called the Indonesian Instructional Designer Association or Asosiasi Pengembang Teknologi Pembelajaran Indonesia, abbreviated as APTPI.
\end{abstract}

Keywords: instructional designer, online learning, blended learning, ICT- based learning model 


\section{EXISTENCE OF PROFESSIONAL INSTRUCTIONAL DESIGNER IN INDONESIA}

\section{Dr. Purwanto}

\section{Introduction}

The presence of Instructional Designer in Indonesia began with the enactment of the MENPAN RI Regulation in 2009. Instructional designer or PTP positions began to be implemented since 2011 with the appointment of a number of civil servants to PTP through inpassing. Since then the number of PTP has continued to increase and spread in various agencies within the Ministry of Education and Culture and in other Ministries and Institutions throughout Indonesia.They work to develop ICT-based learning models and support the tasks of educators in conducting innovative learning using a variety of learning resources and media.PTP acts as a working partner for educators in realizing the application of distance learning models, mixed learning or other ICT-based learning models needed in various types of education ranging from early childhood education, primary and secondary education, higher education and training in professional positions. But because it is relatively new, there are still many people who don't know about this. Therefore this short article will answer the question about PTP. What is the current existence and performance of PTP in Indonesia?

\section{Establishment of PTP}

The Government of the Republic of Indonesia through the Ministry of PAN and RB together with the Ministry of Education and Culture and BKN have managed to regulate and place PTP as one of the professions in the field of education. PTP's position is based on substantive expertise, namely the development of learning technology.

The factors that support the establishment of PTP also stem from the increasing number of educational institutions that apply the blended learning model and utilize more ICT. Many universities have made breakthroughs to organize mixed/hybrid/blended learning models.

The condition of the world of education in Indonesia in the past few decades has enabled the establishment of a new profession in Indonesia, namely instructional designer (PTP). Developing conditions and situations in the field of education. 
Over the past decade there have been developments in the field of ICT that influence and bring changes to the way work, learning methods and ways of life. The presence of connectivity learning theory encourages the development of learning models that integrate technology in it. Connectivism theory develops a deeper understanding of how to learn and gain knowledge by relying on access to online learningresources. Online learning has grown rapidly in recent years. Its application is not only in colleges and schools but also for training and independent learning and lifelong learning.

The factors that encourage the emergence of PTP positions in Indonesia cannot be separated from the development of various factors globally. In Indonesia it is the same as in other countries developing a culture of collaborative work, and for that increasingly requires super specialists. Besides that due to the development of the work area also needs division of labor. Another factor also influences the establishment of PTP is the change in the learning paradigm and the increasing need for learning resources, especially those based on digital.

A variety of new ICTs that offer benefits and attract the attention of students such as the internet, interactive whiteboards are become an integral part of learning. The entry of new media components and ICTs in learning systems has changed the way educators learn and change the way teachers teach. Changes in the learning paradigm have triggered other changes such as changes in the role of teachers and changes in the services of educational institutions.

\section{PTP Jobs and Product}

PTP's task is to develop learning models and learning media. Through the ADDIE process the task is done. Starting with needs analysis, design, production, implementation and evaluation. PTP through its duties is expected to provide solutions to learning problems.

Instructional designer (PTP) produce products in the form of: learning models. learning media, and e-learning applications. These products are needed to support the implementation of learning in various types and levels of education according to the applicable curriculum.

1. PTP products are in the form of learning models. The ICT-based learning model that has been developed by PTP includes a micro-learning model that is applied at the classroom level by educators, up to a macro learning model that 
involves more system components, and its application requires policy makers' decisions.

2. PTP products are in the form of learning media. Various media products have been produced by PTP in Indonesia. A variety of media ranging from simple media, print, audio, audio visual, multimedia and hypermedia. Nowadays, new media is developing known as digital learning object (DLO). Currently learning media products are generally stored in a field that can be accessed and used openly. All kinds of media that can be used freely as a learning resource are called open educational resources (OER).

3. PTP produces e-learning applications. PTP also produces products in the form of applications that are used for ICT-based learning or e-learning. Applications or software are developed according to learning needs and are designed in various forms and are used as learning management tools. The need for learning applications is increasing along with the availability of technological devices (gadgets and computers), diverse and sophisticated.

\section{Current PTP conditions}

As a condition for the implementation of fostering PTP functional positions various implementing regulations are needed. Compiling the regulations for implementing PTP is the task of the Ministry of Education and Culture. The following table explains the set of rules that have been compiled and which are in the process of preparation.

Amount and distribution of PTP

Based on actual data at Pustekkom 2018 National PTP figures are as follows. All existing PTPs are 260 people. They are spread in Pustekkom and UPT Pustekkom, in P4TK, LPMP and Education and Training Center for Education and Culture Staff. Some of them work in universities and in local government. In were about 185 people waiting for the issuance of the appointment decree as PTP.

PTP Development activities that have been carried out by Pustekkom. There are eighteen items of work that must be done by the PTP development agency. Of the total, most (12) have been worked and fulfilled. However, there are still four tasks that are still in process.

\section{PTP: Future Development}

PTP improvements quantitatively and qualitatively are directed in accordance with the government's vision and policy so that PTP is able to make a real contribution to advance Indonesia's national education.

Based on a survey conducted by Pustekkom in 2016 and the results of which have been reported as academic texts at the time of submission of the revised Permenpan, the National PTP needs figures obtained over the next five years are as follows. 
PTP at Kemenristekdikti; 3400 people are needed with details; 250 people at the Development Center in Kemenristekdikti, 150 people at Open University (UT), and 3000 people in all universities in Indonesia (except UT).PTP at Ministry of Education and Training Institutions; 1500 people consisted of 1000 people at the Training Center or Training Center and 500 in the UPT.

So far the need for PTP personnel in various institutions continues to grow along with the increase in the implementation of online training. The PTP needs are partially fulfilled through an inpassing path that opens its opportunity through Permenpan Number 26 of 2016, and is continued with Permenpan Number 42 of 2018. The opportunity to add PTP personnel through inpassing is opened until April 2021.

Please note that during 2017 until 2018, 7 PTP inpassing participant selection tests have been opened with approximately 750 civil servants participating in them. While the number of graduates is around 300 people, and most of them have been appointed as PTP.

The increase in the number was followed by efforts to improve quality and competence, which were carried out through various trainings.PTP competencies continue to be improved in accordance with the demands of work programs that exist in each user institution.

Meanwhile, to organize the best online learning a systematic planning and development process are required. In the university level since 2015 online lecture models have been organized by the college consortium and can be attended by students from different universities. On October 15, 2014 Indonesia Open and Integrated Online Learning (PDITT) was launched and began to be implemented in 2015. The online learning has now changed its name to the Indonesian Online Learning System (SPADA). The implementation of SPADA by Universities and the Directorate General of Higher Education clearly requires good collaboration between lecturers and instructional designers or PTP.The more online lectures held in universities, the higher the need for PTP staff.

Increasing opportunities for PTP to work in Primary and Secondary Education have also grown even bigger. In primary and secondary education there are Open Junior High Schools (SMP Terbuka) and Open High Schools (SMA Terbuka). There are also special programs for students come from outermost, foremost and disadvantaged regions (Daerah 3T) as well as other distance education programs.

PTP also has the opportunity to work in the non-formal education sector and other community education. Various learning resources that enable the implementation of lifelong learning and education for all of these are very necessary. The availability of various learning resources contributes to the increasing number of people pursuing the new competencies required by the new profession. The development of various learning 
resources for this purpose requires public participation and government facilitation. One of the experts who participated was PTP experts.

Then in the field of human development apparatus, especially training civil servants has developed various initiatives for the implementation of online training or blended learning. With the increasing number of training institutions in the ministries and institutions that organize online learning or blended learning, the greater the number of PTP staff recruited and employed in education and training institutions. One of them is through inpassing.

The facts presented above show that the presence of PTP in various educational institutions has become a necessity. However, it should be noted that until now not many training institutions have appointed PTP, but their needs have increased. Some of them are still in preparation.

There is still one obstacle that requires decisions from policy makers. The PTP profession can only be occupied by civil servants, and cannot be occupied by government employees under a contract. This has hampered the growth in the number of PTP, because the number of civil servants is getting smaller. PTP needs will be fulfilled if they can be appointed from contract employees (PPPK).

\section{Role of PTP}

Even though the number of PTPs is still small, they have worked and taken an important role. The following is an example of PTP's performance that should be noted as a proud achievement. PTP in the Ministry of Education and Culture has played a role in developing the Open High School (SMA Terbuka) model which began to be initiated as an effort to realize the 12-year compulsory education. PTP at Kemenristekdikti has participated in managing the Indonesian Online Learning System (SPADA). Likewise PTP in some Pusdiklat has succeeded in developing online or blended training models for civil servants.

Even the PKTBT (online training for CPNS) training model developed by the Pusdiklat with PTP Pustekkomsupport, has won the number one best award in 2018 by the State Administration Institute (LAN).

We believe that one of the efforts in realizing "Making Education 4.0 for Indonesia", is through establishment of PTP. The role of PTP is very important in preparing digital literacy as one of the preconditions for education 4.0.PTP is also expected to act as an innovator in developing learning models that can meet needs at various levels and types of education in Indonesia. With his expertise PTP is able to solve some learning problems, especially those related to quality improvement. 


\section{PTP Existence and Challenges}

The existence of PTP formally as a profession has been known, accepted and considered by the government. However, PTP still has to struggle to improve its performance so that the presence and presence of PTP can be felt by people who receive learning services. To be known by PTP, it must be more productive to produce innovative learning models.

Regarding the role of PTP in the future, many experts expressed optimistic opinions. No doubt the existence of PTP will also be bright if it is able to take the right role.Connie Malamed explains that the fundamental purpose of Instructional Design is to "identify the skills, knowledge and the attitude gaps of a targeted audience and to create, select and suggest learning experiences that close this gap". Complementing the scope and purpose of this definition, Christopher Pappas further elaborates that "Instructional Design aims to compress the learning process and fill the gaps in our knowledge in the most effective way."

\section{EXISTENCE OF PTP}

The existence of PTP in Indonesia will then be determined by how skilled they are in carrying out their duties.If they are able to play a role in making fun e-learning and the learner loves it, then PTP will exist.

Justin Ferriman believes that an Instructional Designer in contemporary times would need to wear multiple hats and juggle roles far more frequently than in the past. Times have changed when proficiency in a couple of core skills sufficed; Instructional Designers must develop skills that allow them to don the roles of a facilitator, researcher, and innovator amongst others.

Connie Malamed is of the view that in the future, Instructional Designers, in addition to creating courses for a specific user profile, would also begin to play a crucial role in enabling learning via online communities, social media technologies, curating content, and providing guidance to faculty and teaching experts on how to generate more relevant content.

According to Shauna Leblanc Vaughan, it will be key for Instructional Designers to acquire familiarity with user experience (UX) to holistically comprehend learners' interactions and responses to content when transmitted over a range of devices.

Other experts in the field like Sahana Chattopadhyay are of the view that there is a massive transformation due in the field of Learning and Development over the next few years impacting learners, instructors, and every other professional that plays a role in 
curating, creating, and designing learning content. Wearable technologies, open resources like MOOC, the rise of self-learners with a consumerist mindset, morphing of the traditional mode of learning with eLearning will blur the demarcations between the two and professionals like Instructional Designers would have to take on the mantle to $\mathrm{d}$ esign and create experiences that are seamless across different ecosystems.

So in order to be able to play a role and exist PTP must be able to face the challenges that exist by continuing to improve competencies and learn new technologies and create innovation.

\section{Conclusion}

The existence of PTP formally as a profession has been known, accepted and considered by the government. However, PTP still has to struggle to improve its performance so that the presence and performance of PTP can be felt by people who receive learning services. To be known by PTP, it must be more productive to produce innovative learning models.

\section{References}

1) Ferriman, Justin, 9 Essentials Instructional Designer Skills, LearnDash, 2013 (https://www.learndash.com/9-essential-instructional-designerskills/?utm_campaign=elearningindustry.com\&utm_source=\%2Fwhat-role-of-theinstructional-designer\&utm_medium=link)

2) Singh, Ravi Pratap, Gaze Into The Future Of Learning With Connie Malamed, ELearning Industry, 2014 (https://elearningindustry.com/gaze-into-the-future-oflearning-with-connie-malamed)

3) Malamed, Connie, What Instructional Designers Do, Starting a Career in Instructional Design, theelearningcoach.com, (http://theelearningcoach.com/elearning_design/is-this-instructional-design/)

4) Pappas, Christopher, What An Instructional Designer Does? 3 Myths Revealed, ELearning Industry, 2013 (https://elearningindustry.com/what-an-instructionaldesigner-do-3-myths-revealed)

5) Vaughan, Shauna LeBlanc, 2016 Instructional Design Trends Compass: Experiences, Ecosystems, Evaluations. Oh My!, ELearning Industry, 2016, (https://elearningindustry.com/2016-instructional-design-trends-compassexperiences-ecosystems-evaluation-oh)

6) Chattopadhyay, Sahana, 4 Reasons Why There Will Be A Learning And Development Transformation, ELearning Industry, 2016, (https://elearningindustry.com/4-reasons-learning-and-development-transformation) 